\section{Experiencia comunitaria cocreativa en la producción de relatos audiovisuales. Una perspectiva de jóvenes víctimas en Norte de Santander, desde la investigación-acción}

\section{Resumen}

Se presentan los resultados del proyecto comunitario de co-creación "Experiencias de Juventud para la Paz", cuyo objetivo principal se centró en proponer alternativas pedagógicas a la Cátedra de la Paz mediante narrativas que parten de la perspectiva de la alfabetidad visual, en la que participaron 25 jóvenes víctimas del conflicto armado, pertenecientes a la Fundación de Artes Empíricas, ubicada en Villa del Rosario, Norte de Santander. La metodología constó de talleres participativos desde la postura de investigación-acción, para movilizar reflexiones críticas y apropiación de técnicas de producción y formación insertas en la cultura audiovisual, derivando en tres cortometrajes argumentales que mostraron las experiencias, memorias y desafíos de los jóvenes, para hacer visibles relatos de su vida barrial y permitiendo expresar racionalidades para construir cultura de paz en el territorio, mediante la aplicación de los componentes de valor de un proyecto audiovisual. Lo que permite concluir, primero, que la Paz es una categoría sistémica que no puede reducirse a la totalidad simple de un saber transmisible, sino a una experiencia pedagógica que debe afectar tanto a los sujetos de enseñanza como de aprendizaje; segundo, el audiovisual planteó nuevas posibilidades a la relación que los participantes tenían con el mundo, encontrando, en esta forma de expresión, la manera de encontrarse y narrarse auténticamente, en el entendido de dejar de ser espectadores y convertirse en autores; finalmente, el reto de generar proyectos que afecten la representación de jóvenes victimas en el discurso audiovisual colombiano.
Juan Diego Hernández Albarracín

Doctor en Ciencias de la Educación. Profesor planta, Universidad Simón

Bolívar, Cúcuta, Colombia.

Correo electrónico:

j.hernandez@unisimonbolivar.edu.co ๑ orcid.org/0000-0003-2517-8393

Google Scholar

María Daniela Ramírez

Lindarte

Magíster en Gestión Cultural y

Producción Audiovisual.

Coordinadora de comunicaciones, Corporación pastoral social de la

diócesis de Cúcuta, Colombia.

Correo electrónico:

comunicacionescospas@

diocesisdecucuta.com

() orcid.org/0000-0001-9543-1150

Google Scholar

Zósimo López Pena

Doctor en Comunicación e Industrias Creativas.

Profesor, Universidad Internacional de La Rioja, Logroño, España.

Correo electrónico:

zosimo.lopez@unir.net

๑ orcid.org/0000-0001-6058-9003

Google Scholar

Recibido: marzo 24 de 2021 Aprobado: junio 23 de 2021

\section{Palabras clave:}

alfabetidad visual, experiencia, cultura de paz, co-creación y producción audiovisual. 


\section{Co-creative community experience in the production of audiovisual narrations. A perspective of young victims in Norte de Santander, from action-research}

\begin{abstract}
The results of the community co-creation project, "Youth Experiences for Peace", whose main objective was to propose pedagogical alternatives to the Chair of Peace through narratives that start from the perspective of visual literacy, with the participation of 25 young victims of the armed conflict members of the Empirical Arts Foundation located in Villa del Rosario, Norte de Santander, are presented. The methodology consisted of participatory workshops from the action-research position to mobilize critical reflections and appropriation of production and training techniques inserted in the audiovisual culture, resulting in three plot short films that showed the experiences, memories and challenges of the young people to make visible stories of their neighborhood life and to allow them to express rationalities to build a culture of peace in the territory through the application of the valuable components of an audiovisual project. This allows concluding that, in the first place Peace is a systemic category that cannot be reduced to the simple totality of a communicable knowledge but to a pedagogical experience that must affect both the subjects of teaching and learning. Secondly, the audiovisual presented new possibilities to the relationship that the participants had with the world, finding in this form of expression the way to meet and narrate authentically in the understanding of ceasing to be spectators and becoming authors and, finally, the challenge of generating projects that affect the representation of young victims in the Colombian audiovisual discourse.
\end{abstract}

Key words:

visual literacy, experience, culture of peace, audiovisual cocreation and production. 


\section{Introducción}

Este artículo recoge algunos resultados de la intervención comunitaria titulada "Experiencias de Juventud para la Paz", desarrollada durante 2019, como un proyecto de gestión cultural y producción audiovisual, que retomó las iniciativas de educación popular de la Fundación Artes Empíricas ${ }^{1}$ y que en alianza con la Universidad Simón Bolívar, la Comisión de la Verdad y el Museo Casa Natal General Santander, procuró la generación de una experiencia pedagógico participativa que ofreció a una comunidad de 25 jóvenes víctimas del conflicto armado $^{2}$ y habitantes del barrio Buena Vista II, en Villa del Rosario, Norte de Santander, un espacio de creación artística alrededor de la expresión de imaginarios sociales, que arrojó, como parte del resultado, tres cortometrajes argumentales escritos y desarrollados por ellos; lo cual, además, aportó a dinámicas de movilidad social al entregar a la comunidad conocimientos y herramientas desde la perspectiva de la alfabetidad visual para el diseño de proyectos culturales, con la pretensión de generar ejercicios audiovisuales propios o vincularse en el futuro a otros con similares intereses.

En consecuencia, se presentan los elementos que constituyeron la discusión sobre la pertinencia de una perspectiva de práctica pedagógica que, a través del dispositivo audiovisual como elemento de mediación, aportó a comprender la Cátedra de Paz, Ley 1732 de $2014^{3}$, desde otra perspectiva, para incentivar una

\footnotetext{
${ }^{1}$ Conformada el 24 de febrero de 2015 en la zona de Buena Vista II por Marta Mora, líder social, víctima del conflicto armado, poetisa y activista de la región, quien desarrolla actividades lúdicas y artísticas de forma descentralizada por todo el departamento. La escogencia de esta comunidad en particular responde al reconocimiento de ciertas herramientas y saberes propios de las prácticas artísticas, que hacen a estos jóvenes poseedores de una sensibilidad dispuesta a la creación.

${ }^{2}$ Es una confrontación sistémica que se puede rastrear desde 1958 entre distintos actores estatales y al margen de la ley (guerrillas, paramilitares, agentes estatales) que por razones ideológicas o económicas configuran ejercicios de poder "que no tiene una modalidad de violencia distintiva. Los actores armados enfrentados han usado y conjugado todas las modalidades de violencia. Todos han desplegado diversas modalidades y cometido crímenes de guerra y de lesa humanidad, haciendo a la población civil la principal víctima del conflicto" (GMH, 2013, p. 20), cobrando a corte de 2012 la vida de al menos 220.000 personas según los informes que recoge el Centro Nacional de Memoria Histórica.

${ }^{3}$ Ley firmada en el marco de los acuerdos de paz entre el Estado colombiano y la guerrilla de las FARC, que dicta la configuración de las Cátedras de Paz en las instituciones de todo el país, involucrando al sistema educativo en los escenarios de posconflicto, como una muestra del interés que hay desde el Estado por recoger todas las miradas posibles del conflicto en Colombia.
} 
cultura de paz y generar espacios de creación nutridos por el acontecimiento de encuentros existenciales en escenarios contemporáneos de aprendizaje y asumir "el llamado a la afirmación de nuestra vulnerabilidad común que implica, simultáneamente, el reconocimiento de nuestra interdependencia y proximidad" (Ruiz y Gómez, 2021, p. 207).

Cuestión por la cual, se pretende: 1) evidenciar aspectos del desarrollo metodológico que dieron viabilidad fáctica a la experiencia de intervención comunitaria; 2) discutir la relación entre cine, alfabetidad visual y gestión cultural, asumidos como potencia para un pensar pedagógico renovado, en cuanto a cultura de paz se refiere; y 3) exponer los resultados del proceso, a partir de las circunstancias que permitieron su realización, dando vida a los productos audiovisuales creados por los jóvenes de la Fundación Artes Empíricas.

\section{Enfoque y desarrollo metodológico}

Los aspectos metodológicos que condicionan esta experiencia comunitaria tuvieron la intervención conjunta de un grupo de profesionales de la gestión cultural, las ciencias de la educación y la producción audiovisual, para responder estratégicamente a los contenidos reglamentados por el Decreto 1038 de 2015, que fueron priorizados en los currículos de las etapas. Con esto, se logró un tejido curricular que abriera vértices y se conectara con las expectativas y discusiones sobre cultura de paz, desde la perspectiva de las comunidades.

Permitió, además, comprender las acciones desarrolladas en el marco de la implementación del proyecto social desde el itinerario y la historicidad que posee la comunidad y las apuestas por elaborar un proceso de trabajo comunitario; sosteniendo así, la necesidad de evidenciar la relación existente 
entre el conocimiento, la práctica y el ser, como elementos para la estipulación de una concepción metodológica inicial, que permitiese a los investigadores planear el ingreso a la comunidad (Tabla 1).

Tabla 1. Articulación del proceso de concepción metodológica

\begin{tabular}{lll}
\hline Conocer & Hacer & Ser \\
\hline $\begin{array}{l}\text { Se pretende conocer la dinámica de } \\
\text { la población que integra la Fundación }\end{array}$ & $\begin{array}{l}\text { Una vez conocido y comprendido el contexto } \\
\text { social, político, económico y cultural de la }\end{array}$ & formación y sensibilización \\
Artes Empíricas, es decir, la realidad & población y del mismo territorio del barrio & la población beneficiaria \\
y el contexto en el que se encuentran & Buena Vista II, se pretende comenzar a & del proyecto fortaleció y \\
inmersos sus integrantes, con sus & influir mediante estrategias socioeducativas & desarrolló valores como la \\
contradicciones, particularidades, & desde la perspectiva de la alfabetidad & reconciliación, solidaridad \\
complejidades, las manifestaciones & visual en su propio entorno, para así & y pluralidad, para \\
objetivas y subjetivas que ha provocado & contribuir a su transformación a partir de la & transformar la violencia \\
en la zona el conflicto armado, la forma & gestación de procesos creativos orientados & simbólica en cultura de \\
en la que se establecen las relaciones & a la construcción de cultura de paz dese la & paz. \\
entre los sujetos mismos que habitan el & perspectiva de la alfabetidad visual de la que & \\
territorio. & se obtuvieron tres cortometrajes. & \\
\hline
\end{tabular}

Fuente: elaboración propia.

Para dar cuenta de la relación entre ser, conocer y hacer, se escogió la investigación-acción, como aquella que ofrece una alternativa de explicación comprensiva de la realidad y, además, una propuesta de transformación y optimización de aquella. De esta manera, se trata de una práctica reflexiva social en la que no existe diferenciación entre la práctica sobre lo que se investiga y el proceso de investigar sobre ella (Latorre, 2005). Hay, en consecuencia, un estudio de una situación social para intentar mejorar la calidad de la acción misma. Su objetivo radica en aportar elementos que sirvan para hacer posible el juicio práctico en situaciones determinadas y la consistencia de las teorías e hipótesis que, siguiendo a Elliot (2005), no dependen tanto de constructos científicos de verdad, como de la utilidad de un mecanismo (en este caso las creaciones audiovisuales) para ayudar a las personas a actuar en el transcurso de sus vidas. 


\section{Proceso metodológico para la intervención: elementos de estructuración curricular}

El diseño del proyecto propuso una estructura curricular dividida en tres etapas: 1) propedéutica, 2) formación en alfabetidad visual y 3) práctica creativa. Dentro de ellas se desarrollaron un total de 12 cursos, cada uno compuesto por seis horas divididas en dos jornadas: mañana y tarde. La primera, constituyó un espacio de exploración teórica y metodológica en el auditorio del museo, mientras que la segunda se trabajó al aire libre, en el Jardín Níspero (Figura 1), escogido estratégicamente para suscitar la movilidad en los jóvenes, así como la agrupación de los mismos en equipos de trabajo, para discutir conceptos previamente desarrollados, a partir de recorrer el contexto museológico de la casa General Francisco de Paula Santander.

Tales espacios, fueron dirigidos por profesionales de amplia trayectoria en las ciencias sociales y de la educación, la producción audiovisual y las artes, constituyendo con ello un tejido vivo que combinó la experiencia académicoinvestigativa, con la necesidad de ir abriendo caminos hacia nuevas formas de entendimiento y creatividad, a partir de la interacción comunicativa con la comunidad. 


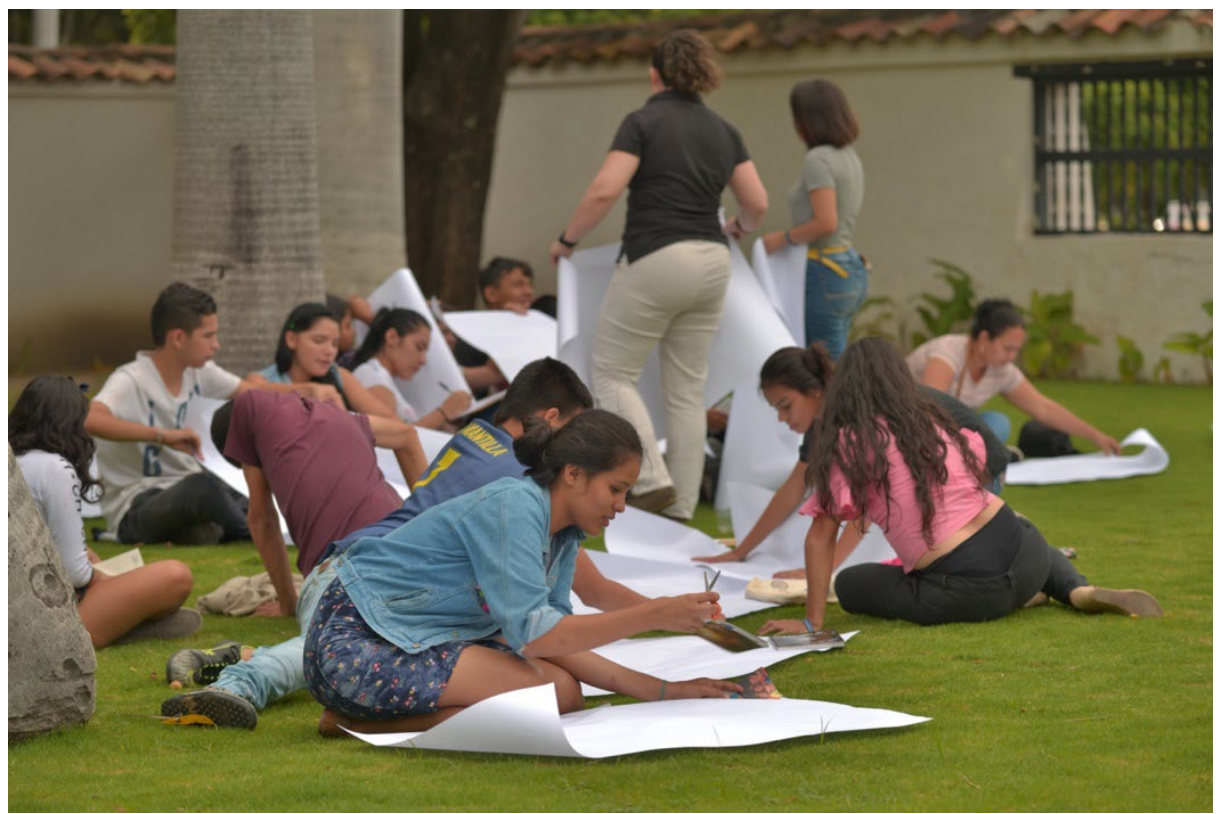

Figura 1. Módulo: La experiencia de sí. Fuente: Javier Ricardo Otero.

Cada jornada fue un espacio de ampliación del conocimiento, a partir de los contrastes pedagógicos insertos en la experiencia de los mundos de vida familiares y barriales de los participantes, con miras a la aplicación del diseño de productos, que hacen parte de la cadena de valor de un proyecto audiovisual: storyline, guion literario, guion técnico, storyboard, plan de rodaje, desgloses y presupuesto. De ahí que se propuso un tejido curricular abierto para viabilizar la experiencia formativa y creativa de los participantes, desde la configuración de tres etapas que potenciaron el ejercicio co-creativo con la comunidad. 


\section{Etapa propedéutica}

Se compone de la intención de ocasionar experiencias conceptuales, creativas y psicológicas, a través de miradas críticas a la Cátedra de Paz para poner en cuestión el mundo de vida propio y de los otros, desde la complejidad devenida del conflicto armado sobre los cuerpos y memorias de los actores sociales participantes. Por tanto, se presentan tres cursos (Tabla 2), cuya diferencia radica en su potencialidad para abrir distintas maneras de ingresar y deambular por las vivencias, una suerte de cartografía que deja ver las distancias entre la yoidad y la otredad (Marcos, 2019), como base primordial para entretejer procesos de creación compleja estipulados en la naturaleza de este proyecto.

Tabla 2. Etapa propedéutica

\begin{tabular}{|c|c|c|c|}
\hline Nombre del curso & Descripción & Perfil orientador & $\begin{array}{l}\text { Componente } \\
\text { Cátedra de Paz }\end{array}$ \\
\hline $\begin{array}{l}\text { Acto de creación: } \\
\text { elementos para } \\
\text { la inmersión } \\
\text { en el lenguaje } \\
\text { cinematográfico }\end{array}$ & $\begin{array}{l}\text { Plantea los elementos iniciales para sumergir } \\
\text { a los actores en las maneras de realización } \\
\text { cinematográfica desde una postura donde la } \\
\text { narración y la potenciación de la imaginación } \\
\text { creativa se superpongan al hacer técnico propio } \\
\text { de los currículos academicistas. Por tanto, } \\
\text { es indispensable un orientador dispuesto a } \\
\text { desmenuzar las dimensiones de la configuración } \\
\text { fílmica, para comunicar condiciones esenciales } \\
\text { del mundo de la creación audiovisual y } \\
\text { establecer agendas de entendimiento desde } \\
\text { la diversidad y pluralidad de la experiencia } \\
\text { con el mundo, que serán complementadas } \\
\text { en los demás cursos que componen la etapa } \\
\text { propedéutica. }\end{array}$ & $\begin{array}{l}\text { Doctor en Pedagogía } \\
\text { y Comunicación } \\
\text { Audiovisual }\end{array}$ & $\begin{array}{l}\text { Diversidad y } \\
\text { pluralidad }\end{array}$ \\
\hline
\end{tabular}


Hernández, J. D., Ramírez, M. D. y López, Z. / Experiencia comunitaria cocreativa en la producción de relatos audiovisuales. Una perspectiva de jóvenes víctimas en Norte de Santander, desde la investigación-acción.

\begin{tabular}{|c|c|c|c|}
\hline Nombre del curso & Descripción & Perfil orientador & $\begin{array}{l}\text { Componente } \\
\text { Cátedra de Paz }\end{array}$ \\
\hline $\begin{array}{l}\text { Contribuciones a la } \\
\text { No Repetición. Un } \\
\text { enfoque desde los } \\
\text { procesos de Paz y } \\
\text { Verdad. }\end{array}$ & $\begin{array}{l}\text { Este curso lo trabajan miembros de la Comisión } \\
\text { para el Esclarecimiento de la Verdad, pues } \\
\text { interesan sus metodologías, información y } \\
\text { tratamiento efectivo con poblaciones que han } \\
\text { sido tocadas directamente por el conflicto } \\
\text { armado. Esto da un carácter diferencial del } \\
\text { trabajo con la comunidad, en cuanto actúa } \\
\text { como dispositivo conceptual para inscribir } \\
\text { el conjunto de la experiencia creativa como } \\
\text { dinámica de sanación, expresión y creación. }\end{array}$ & $\begin{array}{l}\text { Filósofo y } \\
\text { analista territorial } \\
\text { representante } \\
\text { Comisión de la } \\
\text { Verdad. } \\
\text { Historiadora y } \\
\text { asesora experta de } \\
\text { la Comisión de la } \\
\text { Verdad }\end{array}$ & $\begin{array}{l}\text { Resolución } \\
\text { pacífica de } \\
\text { conflictos. } \\
\text { Memoria histórica. }\end{array}$ \\
\hline $\begin{array}{l}\text { La experiencia } \\
\text { de sí: aperturas } \\
\text { existenciales para el } \\
\text { auto-reconocimiento } \\
\text { desde los aportes a la } \\
\text { no repetición }\end{array}$ & $\begin{array}{l}\text { Establece un espacio de auto-reconocimiento } \\
\text { que logre abrir existencialmente las experiencias } \\
\text { internas para proyectarlas como suceso creativo. } \\
\text { Por tanto y debido a la diversidad sensible que } \\
\text { posee la comunidad, es indispensable que } \\
\text { se oriente por un profesional de la Psicología } \\
\text { que conozca y practique los horizontes del } \\
\text { modelo humanista-existencial con trayectoria } \\
\text { profesional en ambientes vulnerables tocados } \\
\text { directamente por el conflicto. }\end{array}$ & $\begin{array}{l}\text { Psicóloga, } \\
\text { Especialista en } \\
\text { Ciencias Sociales, } \\
\text { Magíster en } \\
\text { Orientación de la } \\
\text { Conducta, y Experta } \\
\text { en la metodología } \\
\text { humanista- } \\
\text { existencial }\end{array}$ & $\begin{array}{l}\text { Proyectos de vida } \\
\text { y prevención de } \\
\text { riesgos }\end{array}$ \\
\hline
\end{tabular}

Fuente: elaboración propia.

\section{Etapa de formación en alfabetidad visual}

Está compuesta por cursos que tienen la pretensión de asumir el reto de entregar las bases para la interpretación y creación audiovisual (Tabla 3). En tal sentido, fue importante que los participantes conocieran el lenguaje, la manera de construir un guion, los beneficios del storyboard, la importancia del montaje y algunas posturas prácticas para producir de manera independiente productos audiovisuales. En consecuencia, si bien se buscó incentivar la experiencia narrativa con miras a superponer el arte a la técnica, pensamos que fue importante el tránsito por algunos senderos que hicieron del acto de creación una dinámica de profundidades múltiples, tanto para plantearse problemas como para resolverlos. 
Tabla 3. Etapa de formación en alfabetidad visual

\begin{tabular}{|c|c|c|c|}
\hline $\begin{array}{l}\text { Aprender a } \\
\text { conocer nuestras } \\
\text { imágenes, así como } \\
\text { aprendemos a } \\
\text { conocer nuestras } \\
\text { palabras }\end{array}$ & $\begin{array}{l}\text { Inaugura un territorio diferencial en la operación creativa con } \\
\text { imágenes, pues trabaja la necesidad de contar historias que deben } \\
\text { alejarse de las propiedades del lenguaje hablado. Por tanto, las } \\
\text { descripciones y los objetivos del audiovisual deben abrirse a sus } \\
\text { propios contornos, figuraciones y temporalidades que no están } \\
\text { reglados por el mundo del sentido común o por las dinámicas de la } \\
\text { narración semántica, que posee sus propias características estéticas. }\end{array}$ & $\begin{array}{l}\text { Profesor de } \\
\text { Comunicación } \\
\text { Audiovisual y } \\
\text { Publicidad. }\end{array}$ & $\begin{array}{l}\text { Proyectos } \\
\text { de impacto } \\
\text { social }\end{array}$ \\
\hline $\begin{array}{l}\text { Del relato a la } \\
\text { realización: } \\
\text { aportes desde la } \\
\text { construcción del } \\
\text { guion técnico }\end{array}$ & $\begin{array}{l}\text { Pretende organizar las ideas que fueron surgiendo en el anterior } \\
\text { espacio, para lograr llevarlas al lenguaje audiovisual desde la } \\
\text { organización, primero, de un guion literario y, luego, desde el } \\
\text { técnico. Por tanto, se entrecruza teoría y práctica, para ir produciendo } \\
\text { el itinerario que será definitivo en el rodaje. Es así como el guion } \\
\text { prepara las historias para su tratamiento, lo cual hace de la tarea del } \\
\text { orientador determinante para el éxito del proceso. }\end{array}$ & $\begin{array}{l}\text { Doctor en } \\
\text { Pedagogía y } \\
\text { Comunicación } \\
\text { Audiovisual. }\end{array}$ & $\begin{array}{l}\text { Proyectos } \\
\text { de impacto } \\
\text { social }\end{array}$ \\
\hline $\begin{array}{l}\text { Operaciones } \\
\text { creativas: dibujando } \\
\text { el storyboard }\end{array}$ & $\begin{array}{l}\text { Plantea un ejercicio de desborde, donde los participantes toman eso } \\
\text { que pusieron en palabras para llevarlos al territorio del dibujo, primer } \\
\text { atisbo del trabajo audiovisual. Es interesante cómo se otorgan algunos } \\
\text { elementos técnicos de dibujo con miras a que los actores exploren } \\
\text { otras maneras de representar desde las técnicas, los métodos y } \\
\text { utensilios. Se piensa más como un taller en el que a través del dibujo } \\
\text { se logre integrar con la historia, para hacer del rodaje una experiencia } \\
\text { de reencuentro narrativo. }\end{array}$ & $\begin{array}{l}\text { llustrador, } \\
\text { Licenciado } \\
\text { en Biología } \\
\text { y Química, } \\
\text { Magíster en } \\
\text { Educación. }\end{array}$ & $\begin{array}{l}\text { Proyectos } \\
\text { de impacto } \\
\text { social }\end{array}$ \\
\hline $\begin{array}{l}\text { Tendencias y } \\
\text { alternativas de } \\
\text { narración y montaje } \\
\text { audiovisual (incluye } \\
\text { componente } \\
\text { de alternativas } \\
\text { de financiación } \\
\text { para proyectos } \\
\text { independientes y } \\
\text { uso de tecnologías } \\
\text { móviles) }\end{array}$ & $\begin{array}{l}\text { Pretende establecer algunas condiciones sobre el tratamiento de las } \\
\text { imágenes que permita otorgar cierta espesura creativa a través de la } \\
\text { multiplicación de las opciones para el manejo de las imágenes. } \\
\text { De ahí que la orientación no es únicamente técnica, mediada por } \\
\text { la historia y la teoría del cine, sino también por realizadores que } \\
\text { cuentan las decisiones de montaje de producciones propias. Con } \\
\text { esto pensamos abrir el estatuto de la necesidad creativa, donde los } \\
\text { participantes encuentren distintas formas de contar y organizar las } \\
\text { imágenes, construyendo y deconstruyendo el relato. }\end{array}$ & $\begin{array}{l}\text { Trabajador } \\
\text { Social y } \\
\text { Realizador } \\
\text { Audiovisual. }\end{array}$ & $\begin{array}{l}\text { Proyectos } \\
\text { de impacto } \\
\text { social }\end{array}$ \\
\hline $\begin{array}{l}\text { Ejercicios alternativos } \\
\text { para la producción } \\
\text { audiovisual: una } \\
\text { mirada desde el cine } \\
\text { comunitario }\end{array}$ & $\begin{array}{l}\text { Cierra el proceso previo a la realización, debido a que expone que } \\
\text { el cine más allá de su dimensión artístico-creativa está mediado } \\
\text { por relaciones de poder que devienen sobre todo del mercado. Esto } \\
\text { implica que, pese a la democratización de este a partir de ciertos } \\
\text { dispositivos al alcance de todos, gestionar recursos para hacer una } \\
\text { producción cinematográfica es determinante. }\end{array}$ & $\begin{array}{l}\text { Comunicadora } \\
\text { Social y } \\
\text { Realizadora } \\
\text { Audiovisual. }\end{array}$ & $\begin{array}{l}\text { Proyectos } \\
\text { de impacto } \\
\text { socia }\end{array}$ \\
\hline
\end{tabular}

Fuente: elaboración propia. 


\section{Etapa de práctica creativa}

La tercera etapa es una experiencia co-creativa enfocada en rodar con recursos como celulares, actores naturales, elementos del cine recursivo y demás utensilios que ayuden a operar en este arte a bajo costo (Figura 2). El horizonte será la obtención de tres cortometrajes, en donde la preproducción, producción y posproducción sea un asunto de los participantes, con leves intervenciones del equipo técnico del proyecto para cuestiones de acompañamiento (Figura 3), en función de resolver dudas o potenciar aspectos propios del desarrollo de los cortos que superen a los encargados (Tabla 4).

Tabla 4. Tejido curricular de la etapa de práctica creativa

\begin{tabular}{|c|c|c|c|}
\hline $\begin{array}{l}\text { La importancia de los } \\
\text { roles en la creación } \\
\text { audiovisual: primer } \\
\text { ejercicio de rodaje }\end{array}$ & $\begin{array}{l}\text { Establece la importancia de esclarecer los roles y } \\
\text { funciones de cada uno de los integrantes de los } \\
\text { equipos que van a trabajar en los cortometrajes. } \\
\text { En consecuencia, los orientadores hacen una } \\
\text { exposición de los roles más importantes al } \\
\text { interior de una producción de este talante y, de } \\
\text { acuerdo con la actitud, disposición y necesidades } \\
\text { de los participantes, les asignan una posición } \\
\text { para realizar durante el rodaje. Esto entregó } \\
\text { responsabilidades individuales para la obtención } \\
\text { de una finalidad colectiva, un aspecto ético } \\
\text { que debe ser recalcado constantemente por los } \\
\text { orientadores, pues el éxito del producto social } \\
\text { y audiovisual depende de la capacidad de } \\
\text { asociación y trabajo en equipo. }\end{array}$ & $\begin{array}{l}\text { Comunicadora } \\
\text { Social, y Magíster } \\
\text { en Gestión Cultural } \\
\text { y Producción } \\
\text { Audiovisual }\end{array}$ & $\begin{array}{l}\text { Proyectos de } \\
\text { impacto social }\end{array}$ \\
\hline $\begin{array}{l}\text { Entornos de creación: } \\
\text { momentos de rodaje }\end{array}$ & $\begin{array}{l}\text { Este espacio está abiertamente dispuesto para todo } \\
\text { lo que tienen que ver con las jornadas de rodaje. El } \\
\text { equipo orientador del diplomado debió asegurarse } \\
\text { de acompañar y estar dispuesto a intervenir en } \\
\text { cualquier inconveniente que pueda surgir. Por } \\
\text { esto, las atenciones deben estar dispuestas, pues } \\
\text { debido a los presupuestos, el tiempo y los recursos } \\
\text { tan apretados, es indispensable que los planes de } \\
\text { rodaje se cumplan como fueron establecidos por } \\
\text { los equipos. }\end{array}$ & $\begin{array}{l}\text { Equipo conformado } \\
\text { por comunicadores } \\
\text { sociales, } \\
\text { realizadores } \\
\text { y productores } \\
\text { audiovisuales }\end{array}$ & $\begin{array}{l}\text { Proyectos de } \\
\text { impacto social }\end{array}$ \\
\hline
\end{tabular}


Este curso dependió enteramente de lo sucedido en el espacio anterior. Las imágenes deben estar consignadas y los scripts debidamente ordenados para comenzar los ejercicios de montaje. Aquí se pretendió que todos participen del proceso, pero lógicamente es el director quien tiene el imperio

Organización de las ideas audiovisuales: momentos de montaje de la decisión sobre la forma como se organizan las imágenes.

El equipo técnico acompaña este proceso debido a las complejidades que posee un programa de edición audiovisual, por lo que todo el ejercicio técnico (sonido, coloración, edición, etc.) lo hizo un experto, pero las decisiones son tomadas por los responsables del cortometraje.

Se concibe como la posibilidad de abrir indagaciones, discusiones o propuestas a partir de la experiencia como totalidad, pero también de los productos que arrojó. Se pretendió así, ubicar un entorno de discernimiento para

Ajustes finales

al proceso de posproducción.

Retornos creativos. observar la multiplicidad de lecciones que dejó tanto al equipo técnico, director y acompañante del proceso, como de los participantes en enfrentamientos creativos consigo mismo y con el mundo de los otros.
Equipo conformado por comunicadores sociales,

Proyectos de realizadores impacto social audiovisuales

Equipo conformado por comunicadores sociales,

realizadores

y productores

audiovisuales
Proyectos de

impacto social

Fuente: elaboración propia 


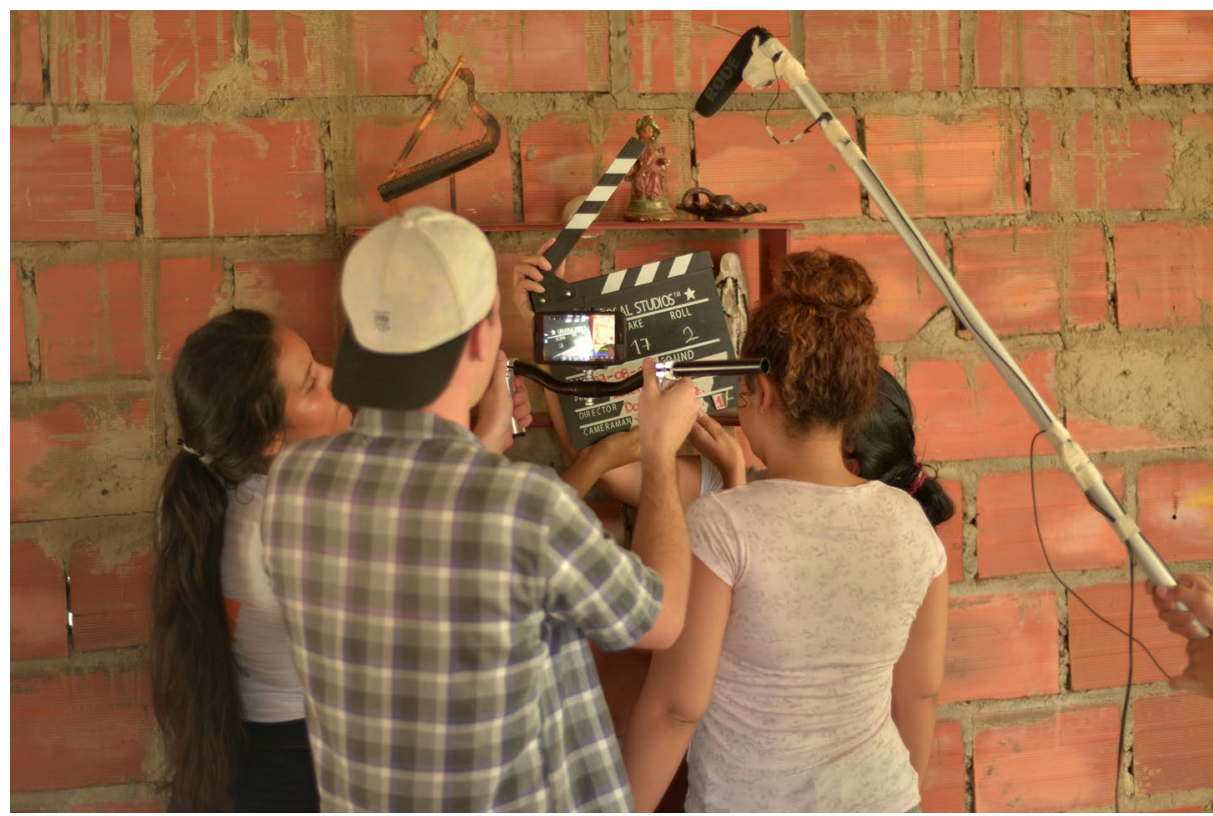

Figura 2. Rodaje del cortometraje "La decisión". Fuente: Javier Ricardo Otero.

\section{Discusión}

Aristas para una reflexión pedagógica de paz mediada por la perspectiva audiovisual: elementos de la experiencia comunitaria

Se parte de hacer visible un diálogo pedagógico, que reconozca la subjetividad como eje que entreteja el logos formativo desde una perspectiva existencial, para abrir caminos a la creatividad. Por esto, el sufrimiento, el aburrimiento y la muerte "generalmente apartad[o]s de la educación y normalmente evitad[o]s 
por la Pedagogía" (Rodríguez et al., 2015, p. 208), son constituyentes primarios de un punto de vista que no busca instrumentalizar al cuerpo y a los sujetos, para perpetuar el discurso social hegemónico a través de la concreción del saber, sino singularizarlo desde la tensión máxima de acercamiento a los estados ontológicas del sujeto que se superponen a la arbitrariedad cultural (Cerón, 2020). Lo cual, se quiere explorar en la racionalidad de esta propuesta, a partir de la mediación audiovisual o cinematográfica, como dispositivo desterritorializador en el marco de un "modelo de saber que hace de todo conocimiento un acto de reconocimiento y del pensamiento una forma de re-cognición" (Marrati, 2006 p. 92), propiciando procesos de tránsito experiencial que se resuelvan artísticamente a través de los ejercicios creativos realizados por los jóvenes.

Por esto, se presenta el curso de acción de una fundamentación que busca recuperar la práctica pedagógica desde "la historicidad de la Pedagogía, tanto para analizarla como saber, como para interpretar sus procesos de formación como disciplina, trabajar con la discursividad de la Pedagogía y analizar la práctica del saber pedagógico en nuestra sociedad" (Zuluaga, 1999, p. 12). Esto se logra configurando formas singulares de enseñanza que orientan una praxis formativa diferente, anclada en el encuentro sintiente con los signos, fuerzas y potencias de la realidad (Pallarès y Villalobos, 2021); permitiendo, desde la virtualidad del diálogo de saberes y la intersubjetividad, posturas divergentes que parten de hacer visible los ejercicios de la libertad y la autonomía en los sujetos de aprendizaje, para convertirse en autores que den vida a sus propias historias. 


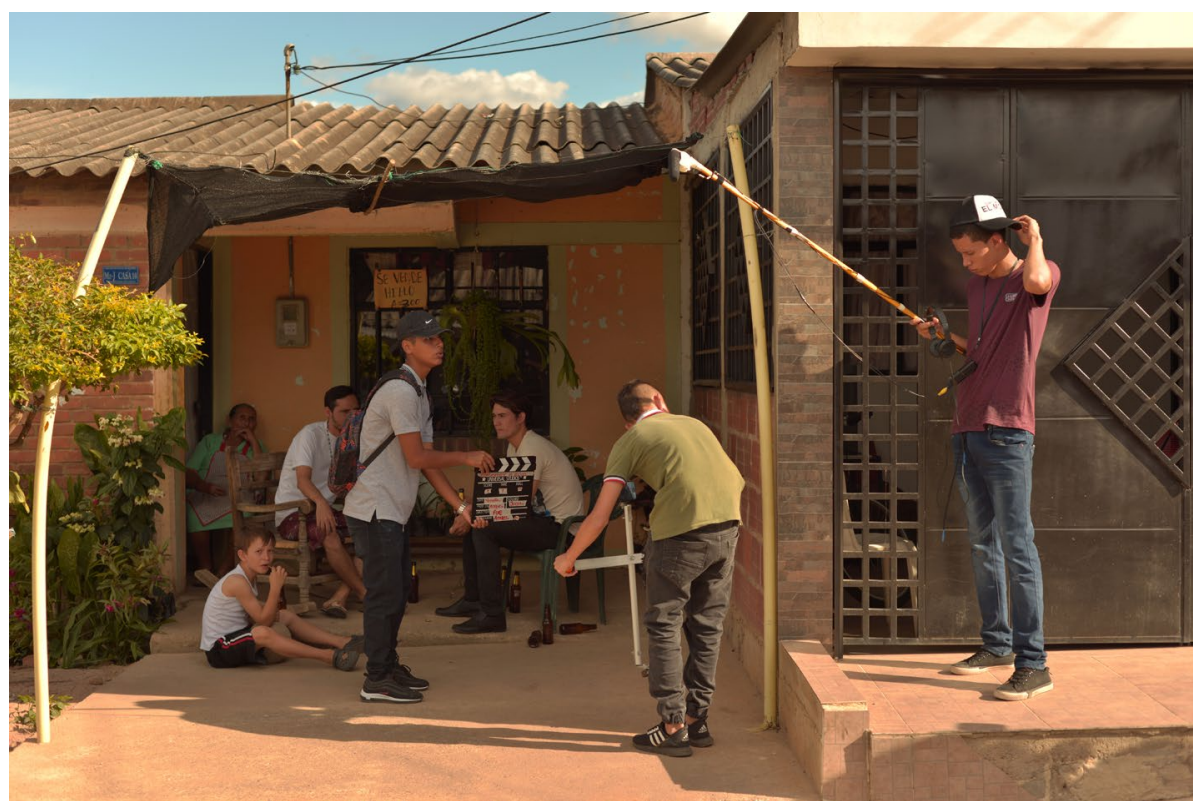

Figura 3. Rodaje del cortometraje "El Mono". Fuente: Javier Ricardo Otero.

Para esto, fue determinante asumir una reflexión permanente sobre la paz y las iniciativas pedagógicas que pudiesen interrumpir e intervenir las expresiones del conflicto en las comunidades. Razón por la cual, el proyecto se desarrolló a modo de capas, donde el concepto, la técnica y la experiencia se combinaban para generar productos audiovisuales que hablaran de las condiciones, prácticas e imaginarios de la vida barrial.

Este asunto, hizo necesario repensar los procedimientos y las herramientas para configurar una pedagogía de paz, que atendió a los requerimientos contemporáneos del conflicto desde una racionalidad abierta, compleja, 
solidaria y democrática, en la que la voz de todos los actores se articuló para aportar a los ejercicios de resolución de conflictos a través de los trabajos audiovisuales.

Por tanto, la discusión se concentró en proponer un proceso de ruptura al concebir el arte "como el territorio donde acontecen encuentros que violentan el pensamiento" (Maldonado, 2008, p. 173), a partir de una dimensión filosófica que forzara la imagen a una contorsión que superara lo concreto de la historia representada del saber, dando cuenta de la paz como una experiencia y el apresurar de un eje sustancial del ingreso de las narrativas audiovisuales al escenario comunicativo, para experimentar aprendizajes a partir de los procesos de la alfabetidad visual, que implican interpretación y generación de imágenes (López, 2017). Por esto, se buscó 'enclasar', esto es, "poner en orden cosas que en apariencia no tienen nada en común" (Deleuze, 2014, p. 605), siendo el caso de la relación cine-escuela-subjetividad, debido a que el cine, según Parra (2016), es la zona indeterminada e inclasificable entre arte, ciencia, técnica y filosofía.

En este caso, se hace referencia a la relación cine-encuentro pedagógico y no narrativas audiovisuales, por ser el primero un concepto que contiene al segundo (Hernández et al., 2019), entonces, fue necesario comprender que los procesos que involucran la apreciación y discusión de las representaciones sociales en la gran pantalla comenzaron por el cine, para dar lugar, más adelante, a dinámicas no pasivas que decantan en la consolidación de narrativas que permitan el trabajo al interior de la alfabetidad visual como una categoría más amplia y directamente relacionada con procesos de producción-creación en los territorios de la democracia cultural. Elementos que, finalmente, fueron decantados al tejido curricular de cada una de las etapas del proyecto. 
Cuestión que hizo crucial reflexionar la potencia de lo audiovisual para incentivar miradas formativas diferentes al interior del proceso, cuyo escenario "no es solo una plataforma de representación, sino centro de encuentros magníficos que producen sentidos" (Parra, 2016, p. 15). En tal razón, interesó observar cómo el mundo de la imagen irrumpió sobre el mundo de vida de los sujetos para deformarlos, contrariarlos y transformarlos, lo cual implicó una "iniciativa de conflicto y coraje, que pretende preservar la fuerza perturbadora de la creación en un contexto históricamente normativo" (Fresquet, 2014, p. 63). En tal sentido, ver cine no es un acto que cubre los tiempos de ocio de la ocupación alienante, tal como se deduce de la concepción crítica de las industrias culturales, sino el epicentro de una nueva relación, que reemplaza el saber de la representación cientificista por un saber pedagógico, comprendido para producir conmociones creativas (Martín-Barbero, 2010) que arrojan al encuentro de signos, fuerzas y afectos que hacen disímiles y complejas las interacciones entre los sujetos.

Lo propio del cine y el audiovisual como irrupción formativa, es su implicación semiótica para construir los significados y significantes que componen el mundo de las imágenes para incentivar alternativas de enseñanza, cruciales para empatizar con los jóvenes en el proceso de creación y propiciar ejercicios de pensamiento a través de las imágenes (Cadús, 2020). Por tanto, integran y despliegan las condiciones de un mundo pedagógico que busca lo exterior, volviéndose interesante "cuando se hace signo y pierde así su unidad tranquilizadora, su homogeneidad, su apariencia verídica" (Zourabichvili, 2004 , p. 51); ocasionando rupturas que incitan los desbordes y extremos del diálogo de saberes, que ingresan para disolver la estructura histórica del aparente orden de la realidad.

Así, enseñar deja de ser un acto de transmisión (Pallarès, 2020), convirtiéndose en la base de un encuentro bajo el desafío de una seña evocadora por parte 
del orientador, que entrecruza las experiencias creativas con la memoria, para producir un territorio de pensamiento desconocido y perturbador respecto al cual hoy debe enfocarse la pedagogía: "el hecho que todavía no pensamos" (Heidegger, 2005, p. 18), o no se hace sobre lo fundamental.

Se parte, entonces, de la mirada crítica sobre la cual la pedagogía moderna no ha procurado vínculos de pensamiento con relaciones anímicas que enfrenten al existente con sus angustias, aburrimientos, tristezas y demás dimensiones de su propia finitud, desde los cuales mover procesos formativos que transformen existencialmente los saberes y las enseñanzas, en función de configurar subjetividades más abiertas e integrales que contemporanicen la situación borde, debido a que "la democratización de una sociedad fracturada por la guerra pasa por la incorporación, de manera protagónica, de los anónimos y de los olvidados a las luchas y eventualmente a los beneficios de las políticas por la memoria" (GMH, 2013, p. 14), como en este caso, de jóvenes víctimas del conflicto armado, que buscan contar la profundidad de sus historias, desde el claro-oscuro de su situación existencial.

En consecuencia, argumentar cómo la experiencia comunitaria, realizada con jóvenes de la Fundación Artes Empíricas, asume una posición racional de comunicación práctica, que se reinventa desde un extremo estético inserto en la cultura audiovisual, posibilita una relación de alteridad que complejiza el enunciado de los saberes y los integra para la transformación de los sujetos de aprendizaje para atrevernos a "reconocer en ese Otro plural no ya un ter-cero entre el yo y el tú, sino el a priori ético transformador" (Marcos, 2019, p. 328), que busca en la creación audiovisual una forma de profundizar y proyectar la complejidad de sus lugares de enunciación.

Propuesto así, asumimos que el proceso pedagógico de la Cátedra de Paz no debe producir un saber teorético, sino elecciones auténticas sobre modos de 
existencia que reconozcan, en este caso, en el audiovisual, una naturaleza creativa que capture su alteridad (Bergala, 2007) para relatarse de otras maneras y tejer sus historias desde la puesta en escena de un ejercicio ético de acompañamiento co-creativo, que buscó esclarecer algo de las oscuridades que habitan en lo recóndito del espíritu humano, a través del dispositivo audiovisual.

\section{Resultados}

\section{Relatos audiovisuales: encrucijadas de la experiencia}

Los participantes de la experiencia construyeron relatos audiovisuales, cuya intención era visibilizar su vida barrial, las situaciones como gestores de paz, así como las experiencias de conflicto en sus territorios. El proceso de creación arrojó seis posibles historias, de las cuales se rodaron tres.

La selección de los guiones procuró acercar a los jóvenes participantes al lenguaje y a las dinámicas del hacer cinematográfico y audiovisual en Colombia, pensadas para garantizar la pertinencia, sostenibilidad y viabilidad de las propuestas; en ese sentido, se le pidió a un representante por grupo (escogido de forma voluntaria dentro de cada grupo) que defendiera las ideas frente a sus compañeros, asumiendo el reto de comunicar, a través de un pitch, la propuesta creativa del cortometraje: duración, personajes y tiempos narrativos. La votación fue democrática entre los miembros directos de la experiencia y el equipo orientador (Figura 4).

Para participar, cada grupo debía presentar el guion literario finalizado, un avance del guion técnico y storyboard (elementos conseguidos durante las etapas de formación). En principio, estaba planeado escoger dos historias, cada una con un millón de pesos (1.000.000 COP) para su ejecución, pero un 
tercero fue seleccionado gracias al apoyo de un patrocinador que se encontraba en el recinto escuchando los pitchs. La sorpresa conmocionó a todo el equipo y se decidió escoger el cortometraje "Soñar" por ser el que mayores avances tenía en la cadena de valor de su proyecto audiovisual.

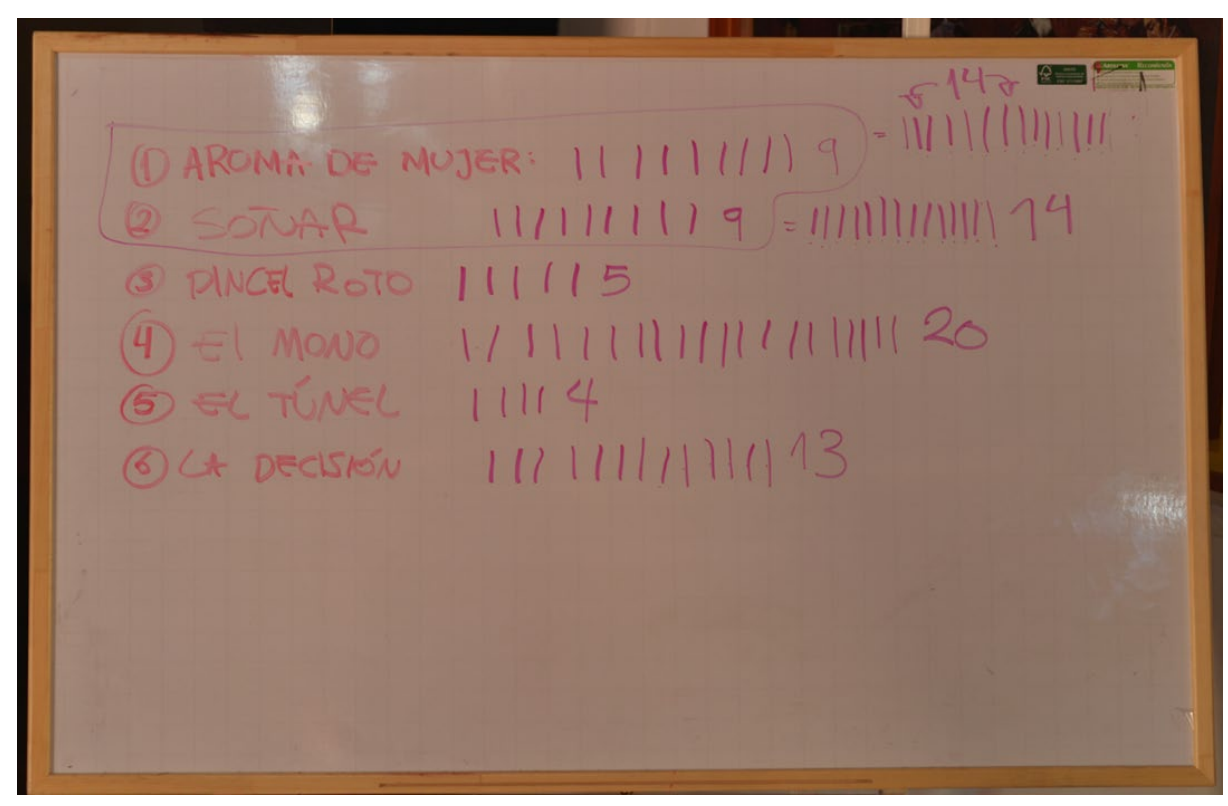

Figura 4. Tablero con resultado de votación luego del pitch. Fuente: elaboración propia

Una vez seleccionadas las historias, el siguiente paso fue establecer los equipos de trabajo y los roles. Para esto, se establecieron cabezas por cada departamento: director, productor, director de fotografía, sonidista y editor, para desarrollar los cortometrajes finales expuestos en la Tabla 5. 
Tabla 5. Descripción de los productos audiovisuales

\begin{tabular}{|c|c|c|}
\hline Título & Sinopsis & Idea original y guion \\
\hline EL MONO & $\begin{array}{l}\text { El Mono es un sicario de } 19 \text { años que se gana la vida evitando que } \\
\text { otros se ensucien las manos. Un día cualquiera, impide que Catalina, } \\
\text { estudiante universitaria de } 19 \text { años y con una vida muy distinta a la } \\
\text { suya, sea violada. El Mono no se considera un héroe, actuó solo por } \\
\text { instinto, tiene un código ético que le impide vulnerar mujeres o niños. } \\
\text { Ahora, Catalina está interesada en conocer más del hombre que la } \\
\text { socorrió, pero él no está dispuesto a abrirse frente a una 'gomela'. }\end{array}$ & $\begin{array}{l}\text { Anyer Arciniegas ( } 17 \text { años) y } \\
\text { Edilianis Lobo (13 años) }\end{array}$ \\
\hline LA DECISIÓN & $\begin{array}{l}\text { Una joven universitaria de } 18 \text { años tiene que lidiar con la universidad } \\
\text { y mantener a su familia económicamente, pues vive junto a su } \\
\text { hermano menor y su madre, quien se encuentra en silla de ruedas } \\
\text { debido a un cáncer. Ella deberá enfrentar un giro en su vida y tomar } \\
\text { decisiones que afectarían decisivamente su futuro y el de su familia. }\end{array}$ & Daniela Díaz (18 años) \\
\hline SOÑAR & $\begin{array}{l}\text { Salomé, una chica de } 15 \text { años que ama el arte, cuando menos lo } \\
\text { espera, su padre, don Mateo, hará que sus sueños se desmoronen } \\
\text { porque él odia todo lo relacionado con el arte y no permitirá que su } \\
\text { hija se convierta en una "buena para nada". Un giro extraordinario en } \\
\text { esta historia jugará a favor de Salomé y así le demostrará a su padre y } \\
\text { al mundo que del arte... ¡SÍ SE PUEDE VIVIR! }\end{array}$ & Alexandra Díaz (18) años \\
\hline
\end{tabular}

Fuente: elaboración propia.

Por tanto, la experiencia creativa desarrollada se centró en desarraigar esas voces subalternas que no son escuchadas, reconocidas y están ausentes de los escenarios de interés cultural, para que rodaran sus historias. Por esto, las etapas descritas buscaban abrir el mundo de las vivencias para que los aprendizajes, lejos de desplazar la memoria por un nuevo saber, se complementaran para ubicar al sujeto en posiciones donde fuese posible verse y narrarse, fortaleciendo así la idea de una "educación humanizada que no se puede reducir exclusivamente al campo educativo, pues se hace necesario generar marcos de representaciones eficaces en el seno de la sociedad y la cultura" (Pallarès, 2020, p. 21). 
Esto permitió una escucha activa sobre el mundo de la vivencia propia, la de los otros y la necesidad de generar apuestas creativas (Herreras y García-Granero, 2020), que fuesen contadas desde el audiovisual. Por tanto, cada historia estaba compuesta de la complejidad experiencial, la dimensión técnica fruto de los aprendizajes y el talento para articularlas en un producto comunicable, pues como menciona uno de los participantes:

\footnotetext{
Hoy he aprendido muchas cosas que permiten introducirme en la historia y cultura de las personas. No siempre conocemos las historias de los otros y siempre dedicamos más tiempo a juzgar personas diferentes a nosotros. Me comprometo a ayudar a las personas para darle valor a su cultura. (Informante 1, Curso 'Contribuciones de No Repetición', 7 de julio de 2019)
}

De ahí, que tanto "El Mono", como "Soñar" y "La decisión", aunque narran fragmentos muy específicos de la vida de sus creadores, fueron fácilmente apropiados por los demás miembros del equipo, pues hacían parte de la cultura barrial, una suerte de vivencia colectiva que los tocaba existencialmente. Por lo que ideas como el sicariato, la superación de las adversidades y la búsqueda incansable de los sueños, fueron una constante que acompañó a los jóvenes, primero como eventos traumáticos y, luego, ya racionalizados, dialogados y convertidos en historias, como elementos dispuestos para su transformación desde el audiovisual; lo cual, trasciende el goce estético hacía un compromiso mayor por una vida estética (Tirado, 2019), pues como asegura otro de los participantes: "Me llevo la esperanza de tratar de mejorar el barrio. Que todos tenemos los mismos derechos, pero pensamos distinto. Quiero seguir aprendiendo más para poderlo enseñar allá" (Informante 2, Curso 'Acto de creación', 6 de julio de 2019). 
Fue importante, además, el desarrollo de habilidades comunicativas que tomaron fuerza a medida que avanzaban los cursos y se tomaban confianza, pues no únicamente interesaba la competencia o la evidencia plena y vertical del aprendizaje, sino que hicieran patente necesidades existenciales propias, para contar historias desde los dispositivos dispuestos para ello (Figura 5). El espacio para desarrollarlo fue emocionante, debido a que instó a los equipos a prepararse para comunicar la necesidad de rodar su cortometraje, lo cual demostró responsabilidad y sensibilidad artística para buscar referentes y hacerlos parte de su proceso.

Películas como "Billy Elliot", "Lalaland" o "La vendedora de rosas" establecieron horizontes estéticos iniciales, tal vez, desde el influjo que sus historias podrían tener desde el cine de amplio público, pero que una vez inmersos en los ejercicios de guionización y rodaje se fueron desdibujando, para dar paso a componentes más propios en la categoría de la alfabetidad visual, que fueron determinantes para traducir el carácter de los personajes, la ubicación de los planos, los movimientos de cámara, etc. Cuestión por la cual, cada cortometraje fue una dimensión propia de la experiencia, que habla de las crisis, los aprendizajes y la transformación de los participantes. 


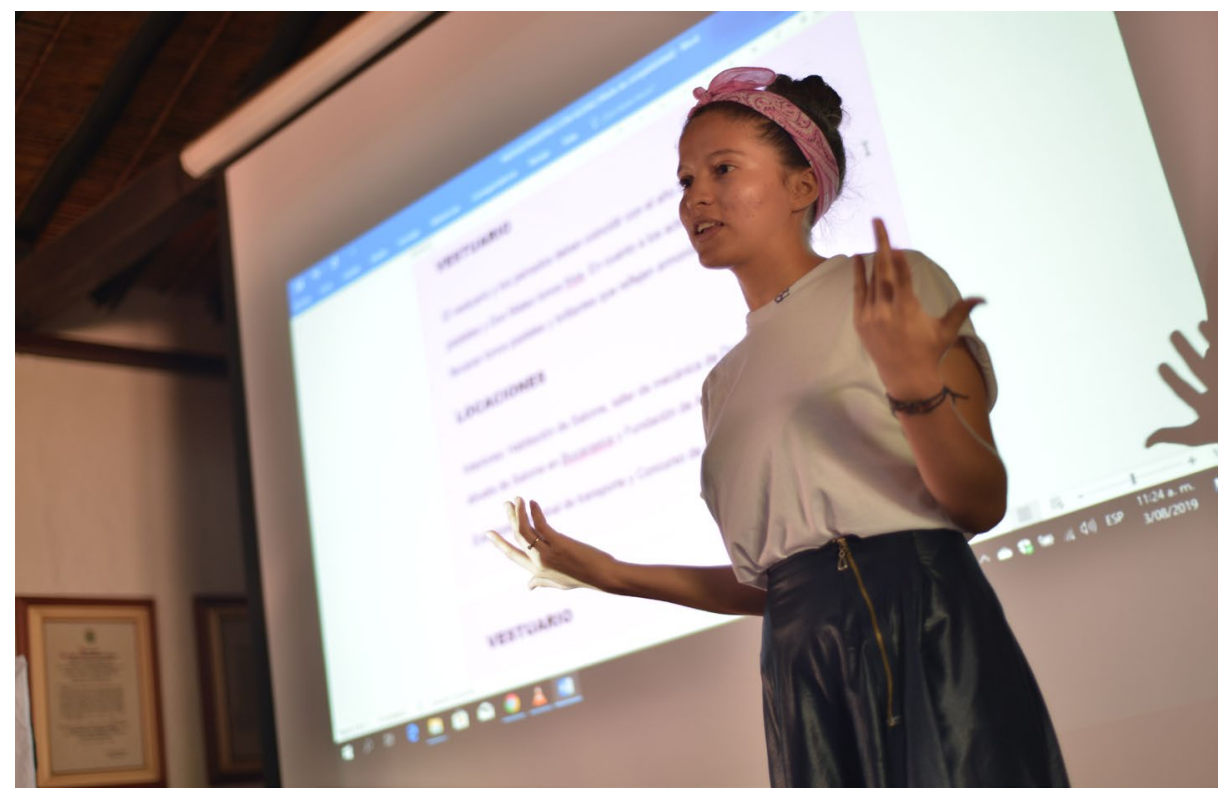

Figura 5. Experiencia propuesta de dirección. Fuente: Javier Ricardo Otero.

En consecuencia, los rodajes fueron desarrollados enteramente en y con la comunidad, integrados por vecinos, padres de familia y amigos de todo tipo, que fueron directa o indirectamente protagonistas de las historias y de las grabaciones de los cortometrajes. Un asunto significativo, que representó los entornos, como una dimensión de lo propio que es menester proteger y desarrollar para poder convivir, como lo refleja un participante en uno de los encuentros luego del rodaje: "en este momento trabajamos convivencia desde el arte, olvidamos muchos problemas que hemos pasado y cuando uno está en lo que le gusta se olvida de lo malo. Eso pienso que es la convivencia" (Informante 3, Curso 'La experiencia de sí', 13 de julio de 2019). 
Cada historia es un relato de la vida barrial, un testimonio de los conflictos, las esperanzas y ausencias que dibujan un escenario desde la voz misma de sus actores. Por esto, la intención de la producción es hacer primero un circuito de exposición en el barrio Buena Vista II, que permita a sus habitantes verse en el reflejo del producto audiovisual y discernir acerca de las historias que provienen de sus mismos entornos. Lo cual, configura un ejercicio ético, en el que la comunidad sea protagonista inicial de cualquier instancia de circulación.

Así, el proyecto expande la idea misma de lo audiovisual hacia el de la alfabetidad visual, pues lejos de ser un mundo aparte, exclusivo y costoso para la producción creativa, fuese posible configurar un dispositivo pedagógico abierto para el tratamiento y comunicación de los conflictos y su traducción existencial desde este arte. Por esto, cada uno de los cortometrajes es un documento que habla y refleja la complejidad de la vida barrial y la expresión de esa subjetividad interna, condenada a no contar sus historias, con las singularidades, sensibilidades y tesituras interpretativas que contiene.

Los participantes debieron enfrentarse a distintos retos que desafiaron sus capacidades y mayores miedos, uno de ellos el trabajo en equipo y la confianza en el otro, pues en el desarrollo de un proceso audiovisual cada miembro del equipo es importante, un engranaje que se detiene si no fluye el trabajo cooperativo. Para la selección de los roles, cada participante se postuló de manera voluntaria; en el caso de "Soñar" y "La decisión", la dirección fue asumida por sus guionistas originales, ambas mujeres, hermanas y mayores de edad. Para el caso del cortometraje "El Mono", la dirección, guion e idea original pertenecieron a tres personas diferentes, lo que provocó en distintas ocasiones conflictos creativos. 
El siguiente paso consistió en la planeación de las propuestas creativas de cada departamento, estableciendo atmósferas narrativas, paletas de colores, intenciones en el sonido directo, manejo de la luz y el encuadre, presentando referencias de películas que eran similares a sus historias. En el caso de "Soñar", las referencias fueron direccionadas a la estética visual del cortometraje, haciendo énfasis en tonos pasteles, referenciando "Lalaland" de Damien Sayrey y "Billy Elliot" de Stephen Daldry. Para el equipo de "La decisión", las referencias se enfocaron en la construcción del personaje principal, atendiendo a sus emocionalidades, carácter y contexto social, con la película "Roma" de Alfonso Cuarón, en la que su protagonista comparte la condición de vulnerabilidad de Andrea, heroína del corto. El equipo de "El Mono" presentó propuestas enfocadas en la representación audiovisual de conflictos sociales latinoamericanos y los mundos de vida barriales, con películas como "La vendedora de rosas" de Víctor Gaviria y "Ciudad de Dios" de Fernando Meirelles y Kátia Lund.

La convocatoria para el reparto de los cortometrajes fue abierta, con la asistencia de artistas de distintas zonas de Cúcuta y su área metropolitana. Fue realizada en el coliseo del Morichal, del barrio Buena Vista II, para la selección de los actores a través de dos instancias, la primera, una entrevista simulada con el personaje y, la segunda, una interpretación de escena.

Para todos los equipos el principal reto fue enfrentarse a las limitaciones de tiempo y dinero, pues debían con un millón de pesos cubrir gastos logísticos y representativos del proyecto, con un tiempo de una semana para realizar la producción de campo y desarrollar la etapa de preproducción, y un máximo de 12 horas para el rodaje en el transcurso de un día. 
La asignación del recurso económico, para la producción de cada propuesta, fue posterior a la entrega de los productos realizados durante los módulos teóricos, que correspondían a los procesos de preproducción: guion literario, guion técnico, storyboard, presupuesto y propuestas artísticas por departamento, haciendo énfasis en una propuesta de dirección sólida. El primero en presentar todo fue el equipo de "Soñar", que por temas logísticos y una propuesta de arte muy elaborada no pudo iniciar; por lo que el equipo de "La decisión" asumió el reto comenzar. El rodaje fluyó con espontaneidad, con el apoyo de un patrocinio gestionado por la productora general, quien junto con la directora lograron distribuir los tiempos de manera precisa y eficaz, grabaron en cuatro locaciones distintas y terminaron antes, según los tiempos del plan de rodaje.

Por otro lado, el cortometraje "El Mono" representó un reto de producción, debido a los conflictos creativos entre los miembros del equipo, quienes se negaban a cooperar para la construcción de una narrativa que integrara las visiones de dirección e idea original. A esto, se sumó la desconfianza en el productor general para administrar los recursos, por lo que, a solicitud del equipo, la producción general fue asumida por la productora de "La decisión", quien tuvo un día para solucionar los problemas logísticos del equipo. Sin embargo, luego de varios encuentros grupales, los conflictos internos pudieron solucionarse y se cumplieron los planes de rodaje.

Cada etapa del proceso aquí relatada, constituyó un tejido experiencial que hizo protagonista las historias del barrio, las violencias, los procesos de resiliencia y los desafíos que circundan sus mundos de vida. Así, se obtuvieron tres productos que cumplieron con el objetivo de convertir en autores a un grupo de jóvenes, con la expectativa de que lo aprendido durante las jornadas amplíe perspectivas e influya positivamente en el territorio, para contagiar, con la consigna del relato propio, iniciativas para la construcción de cultura de paz. 


\section{Conclusiones}

Este proyecto permitió tramar distintos aprendizajes para quienes hacían parte de la producción, desde el ejercicio mismo de autoevaluación y sistematización. La experiencia es basta, debido a la confluencia de mundos de vida tan complejos, que viéndose reunidos para tramar relatos conjuntos, en muchas ocasiones, como las relatadas en el apartado anterior, crearon roces y discrepancias entre los equipos.

Hay retos en todas las materias, concernientes a la gestión cultural, los horizontes epistémicos y metodológicos, el tratamiento psicológico con jóvenes víctimas, las huellas de la violencia y el contexto barrial, que otorgaron la oportunidad a los investigadores de leerse a sí mismos desde otras orillas, pudiendo, en el camino de deconstrucción, tejer mayores aprendizajes sobre la riqueza de estos imaginarios, para tramar nuevas alternativas e intervenir la cultura de paz.

Asimismo, fue importante el trabajo en equipo de distintas disciplinas, que aportaron a la comprensión de la paz como una categoría sistémica, que no puede reducirse a una totalidad simple. De ahí, la confluencia de distintos discursos devenidos de la filosofía, el audiovisual, la comunicación social, la gestión cultural, la psicología, la historia y la pedagogía, para dar ese carácter a la reflexión y posterior creación sobre la misma.

Escuchar con atención cada relato fue determinante para tejer relaciones con los jóvenes, pues así sintieron que más que sujetos de observación científica estaban tendiendo líneas, tanto para sus aprendizajes como para hacer nuevas relaciones, elemento propio de una convivencia vista en procesos horizontales, donde prima la empatía y el reconocimiento del otro. 

audiovisuales. Una perspectiva de jóvenes víctimas en Norte de Santander, desde la investigación-acción.

La idea de una pedagogía para la paz tenía que ver, sobre todo, con la traducción y discusión que cada uno hacía de ella desde la perspectiva de la alfabetidad visual, tratándose, como expone un participante, "no sé cómo explicarlo, pero me gustó eso de que hay que sacarlo todo de adentro para que nazcan cosas nuevas. Porque nadie quiere que adentro algo se muera" (Informante 4, Curso 'La experiencia de sí', 13 de julio de 2019). Por esto, no nos interesaban los manuales o las definiciones totales, sino la puesta en marcha de todo un componente vivencial, que finalmente fue representado a través del audiovisual.

El audiovisual planteó nuevas posibilidades a la relación que los participantes tenían con el mundo. Encontrando así, en esta forma de expresión, la manera de encontrarse y narrarse auténticamente, en el asunto de construir una verdad más propia, como bien menciona una de las participantes: "mi verdad es poderme responder de dónde vengo, quién soy y para dónde voy, se trata de ser honesto consigo mismo y con los demás, no aparentar" (Informante 5, Curso 'Aprender a conocer nuestras imágenes', 14 de julio de 2019). Un asunto que, a nuestro juicio, fue el eje que guio cada uno de los productos.

Fue así como el dispositivo audiovisual se convirtió en el eje movilizador para el relato de cada uno de los participantes, con todas las implicaciones y complejidades que pudiese contener. Por esto, interesaban los testimonios, la mirada amplia de una colectividad que necesita contarse para salir de la invisibilidad, porque "es vital que se produzcan relatos desde la memoria plural y heterogénea. El relato de los jóvenes, de ustedes, el testimonio que quiere dejar un colectivo como el de ustedes", como exponía, en uno de los encuentros, el representante de la Comisión de la Verdad (Miguel Grijalba, investigador Comisión de la Verdad, 7 de julio de 2019). 


\section{Referencias}

Bergala, A. (2007). La Hipótesis del Cine. Pequeño tratado sobre la transmisión del cine en la escuela y fuera de ella. Editorial Laertes.

Cerón, A. (2020). La construcción del objeto de estudio. Lecciones epistemológicas a partir de la obra de Pierre Bourdieu. Cinta moebio, 67, 75-84.

Cadús, R. (2020). Filosofía del cine. El pensamiento por otros medios. Revista Eidos, 33, 53-64.

Deleuze, G. (2014). Cine II. Los signos del movimiento y el tiempo. Editorial Cactus.

Elliot, J. (2005). El cambio educativo desde la investigación-acción. Morata.

Fresquet, A. (2014). Cine y educación: La potencia del gesto creativo. Editorial ocho libros.

GMH. (2013). ¡Basta Ya! Colombia: memorias de guerra y dignidad. Imprenta Nacional. http://www.centrodememoriahistorica.gov.co/descargas/informes2013/bastaYa/basta-yacolombia-memorias-de-guerra-y-dignidad-2016.pdf Heidegger, M. (2005). ¿Qué significa pensar? Editorial Trotta.

Hernández, J., Ramírez, M., Álvarez, C. y Garavito, J. (2019). Entornos de desterritorialización y contrahegemonía: una mirada existencial a la Pedagogía de los encuentros desde la imagen-cine. Utopía y Praxis Latinoamericana, 87, 53-64.

Herreras, E. y García-Granero, M. (2020). Sobre verdad, mentira y posverdad. Elementos para una filosofía de la información. Bajo Palabra, Revista de Filosofía, 24, 157-176.

Latorre, A. (2005). La investigación-Acción. Conocer y cambiar la práctica educativa. Editorial Grao.

López, R. (2017). Fotografía, alfabetización visual y educación en diseño. Revista Inventio, 13(31), 65-69.

Maldonado, J. (2008). Música y creación: un sentido en el pensamiento de Gilles Deleuze (tesis doctoral). Universidad Autónoma de Madrid.

Marcos, J. (2019). La Totalidad dominante desde Dussel como generadora de alienación identitaria. Encuentros: Revista de Ciencias Humanas, Teoría Social y Pensamiento Crítico, 9, 27-40. 
Martín-Barbero, J. (2010). De los medios a las mediaciones. Comunicación, cultura y hegemonía. Anthropos.

Marrati, P. (2006). Gilles Deleuze. Cine y filosofía. Ediciones Nueva Visión.

Pallarès, M. (2020). Educación humanizada. Una aproximación a partir del legado de Heinrich Rombach. Estudios sobre educación, 38, 9-27.

Pallarès, M. y Villalobos, J. (2021). Educación de la memoria desde la literatura: pasado, (re) interpretación del presente y el recuerdo como praxis de formación. Revista Interdisciplinaria, 38(1), 69-84.

Parra, J. D. (2016). David Linch y el devenir cine de la filosofía. Instituto Tecnológico Metropolitano.

Rodríguez, P., De la Herrán, A. y Cortina, M. (2015). Pedagogía de la muerte mediante aprendizaje de servicio. Educación XX1, 18(1), 189-212.

Ruiz, A. y Gómez, S. (2021). Reimaginar una comunidad sobre las bases de la vulnerabilidad. Reflexiones desde Judith Butler. Tópicos, Revista de filosofía, 60, 201-228.

Tirado, V. (2019). Implicaciones para la estética del pensamiento de Xavier Zubiri. Revista Pensamiento, 75(286), 1127-1147.

Zourabichvili, F. (2004). Deleuze. Una filosofía del acontecimiento. Amorrortu editores.

Zuluaga, O. (1999). Pedagogía e historia. Editorial Siglo del Hombre.

Cómo citar: Hernández, J. D., Ramírez, M. D. y López, Z. (2022). Experiencia comunitaria cocreativa en la producción de relatos audiovisuales. Una perspectiva de jóvenes víctimas en Norte de Santander, desde la investigación-acción. Revista KEPES, 19(25), 15-45. https://doi.org/10.17151/kepes.2022.19.25.2 